\title{
Protection Method Based on Wavelet Entropy for MMC-HVDC Overhead Transmission Lines
}

\author{
Weibo Huang, Guomin Luo*(D), Mengxiao Cheng, Jinghan He, Zhao Liu (D) and Yuhong Zhao
}

\section{check for}

updates

Citation: Huang, W.; Luo, G.; Cheng M.; He, J.; Liu, Z.; Zhao, Y. Protection Method Based on Wavelet Entropy for MMC-HVDC Overhead Transmission

Lines. Energies 2021, 14, 678.

https://doi.org/10.3390/en14030678

Academic Editor: Adam Dyśko

Received: 9 November 2020

Accepted: 27 January 2021

Published: 28 January 2021

Publisher's Note: MDPI stays neutral with regard to jurisdictional claims in published maps and institutional affiliations.

Copyright: (C) 2021 by the authors. Licensee MDPI, Basel, Switzerland. This article is an open access article distributed under the terms and conditions of the Creative Commons Attribution (CC BY) license (https:// creativecommons.org/licenses/by/ $4.0 /)$.
School of Electrical Engineering, Beijing Jiaotong University, Beijing 100044, China; 15117384@bjtu.edu.cn (W.H.); 19121415@bjtu.edu.cn (M.C.); jhhe@bjtu.edu.cn (J.H.); 98930225@bjtu.edu.cn (Z.L.); 19126205@bjtu.edu.cn (Y.Z.)

* Correspondence: gmluo@bjtu.edu.cn or guominluo@hotmail.com; Tel.: +86-10-5168-3740

\begin{abstract}
Recent technological developments in modular multilevel converter-based high-voltage direct current (MMC-HVDC) transmission systems have shown significant advantages over the traditional HVDC and two-level voltage source converter (VSC) transmission systems. However, there are a lack of studies on the protection methods for MMC-HVDC overhead lines where the protection method should be able to provide a fast and accurate response and be able to identify lightning strikes. In this paper, a wavelet entropy-based protection method is proposed. Due to the capability of revealing time-frequency distribution features, the proposed protection method combines wavelet and entropy to identify the time-frequency characteristics of different faults. Simulation results show that the proposed method can accurately and quickly determine the types of faults or disturbances with appropriate noise tolerance. In addition, the impact of the ground resistor and fault distance on the performance of the proposed method is studied.
\end{abstract}

Keywords: wavelet entropy; transient component; MMC-HVDC; protection

\section{Introduction}

In the last two decades, considerable progress has been made in the development of voltage source converter-based high-voltage direct current (VSC-HVDC) transmission systems. It is regarded as a promising solution for controlling real and reactive power and reducing losses. Among the different design topologies of VSCs, the modular multilevel converter (MMC) has many advantages, such as modular design, good scalability, low switching frequency, and few harmonic injections [1-3]. It serves as an effective solution for the large capacity and long-distance transmission systems which connect large-scale renewable energy resource centers in western China with the load centers on the eastern coast of China. At the same time, it improves the flexibility and reliability of the power grid operations [4,5]. Comparing with the traditional line-commuted converters (LCCs), VSC-based converters introduce completely different fault characteristics [6]. Especially, for a MMC-based HVDC system, fast and reliable protection is required to eliminate huge fault currents and discriminate transient disturbances. As a result, the protection methods of the traditional HVDC cannot be applied to MMC-HVDC systems. It is necessary to study the fault characteristics of the MMC and propose a protection method for the MMC-based transmission lines.

In traditional LCC-based HVDC transmission systems, the fault current is fully controllable, so line protection does not need to be very fast $[7,8]$. In the symmetrical monopole MMC-HVDC system, when a pole-to-pole fault (PPF) occurs, the bridge arm sub-module (SM) has a discharge circuit, which causes the fault current usually to climb to tens of times the rated current in a few milliseconds [9,10], and the AC power will feed to the fault point through the freewheeling diode. That is, the fault current is uncontrollable. Therefore, it is necessary to detect and isolate DC faults as fast as possible, such as in $3 \mathrm{~ms}$ [11,12]. In addition, when a pole-to-ground fault (PGF) occurs, the bridge arm SM has no discharge circuit. It will only cause small current fluctuations during the transient 
period, which cannot easily be detected. Furthermore, the transient characteristics caused by lightning faults and lightning disturbances are also slight fluctuations in the current. Their characteristics are very similar and need to be effectively distinguished.

In existing LCC-based HVDC projects, the time of traveling wave protection is about $10 \mathrm{~ms}$, and the action time of differential under-voltage protection is about $20 \mathrm{~ms}$ [13-16]. Compared with traditional HVDC, when a PPF occurs in MMC-HVDC, the fault current rises rapidly, which requires higher protection speed and sampling frequency. In this case, the reliability and sensitivity of traveling wave protection and differential under-voltage protection will be reduced. In addition, in terms of the transient recognition of lightning strikes, traditional LCC-based HVDC protection methods mainly distinguish between lightning and faults from the perspective of frequency domain spectrum characteristics or time domain waveform characteristics. However, under short time window scenarios, the resolutions in the frequency domain and discriminations in the time domain waveform are both reduced. Therefore, the protection method of the traditional LCC-based HVDC system does not work for the MMC-HVDC system. New requirements are put forward for the identification of interference from lightning strikes and noise. Compared with the traditional LCC-based HVDC system, the protection method of the MMC-HVDC system needs to consider the reliability of protection and the accuracy of lightning identification at extremely fast speeds.

In recent years, research on the protection of MMC-HVDC transmission lines mainly includes protection methods based on sudden changes of voltage or current protection $[17,18]$, pilot protection [19-21], and traveling wave protection and its improvement methods [22-24]. Among them, the sudden change in voltage or current protection is based on the protection principle of single-ended electrical information. It has extremely fast action speed and is also sensitive. The pilot protection improves the reliability of the protection through the comparison and processing of double-ended information. Traveling wave protection uses corresponding mathematical methods to extract and analyze the high-frequency characteristics of transient traveling waves, such as amplitude, polarity, duration, etc., which has an extremely fast speed for fault detection. However, existing studies still have the following shortcomings: firstly, some protection methods do not consider the impact of lightning disturbances; secondly, some protection methods adopt double-ended information, which might not meet the requirements of the MMC-HVDC system for primary protection speed; finally, some protection methods need to be strengthened in terms of tolerance to ground resistor and anti-interference ability. In general, the protection method of MMC-HVDC is not yet mature and needs further study. Therefore, this article pays more attention to how to improve the reliability of protection and the ability to identify lightning strikes and interference when the protection satisfies high-speed mobility.

In MMC-HVDC systems, different faults have different transient characteristics and different time-frequency distributions. Some faults have similar time domain waveforms, but their frequency domain distributions are different. Therefore, it is possible to propose a protection method based on the difference in time-frequency distribution. The existing signal analysis tools include Fourier transform, Hilbert-Huang transform, S transform, etc. They are the mainstream methods in the field of power system relay protection. However, the amplitude and ratio are usually used as the classification criteria, and consider fewer influencing factors. When considering the influence of factors such as noise and lightning, its setting calculation is complicated, and there are many simplified and equivalent treatments. Its stability and reliability need to be improved. Wavelet transform, a time-frequency analysis method, has the characteristics of multi-resolution analysis, and a strong ability to represent information $[13,25,26]$. Entropy is a tool to measure the disorder degree of the whole system [27-29]. Wavelet entropy is a combination of wavelet transform and information entropy. It can not only achieve the purpose of information fusion but also analyze the mutation signal more effectively [30,31]. It has been gradually applied in image processing, stock market forecasting, biology, machinery, power systems, and 
other fields, with good achievements [32,33]. It has advantages in characterizing system distribution characteristics and degree of disorder.

In this paper, wavelet entropy is used to represent the characteristics of different fault transient characteristics, which can not only meet the requirements of the MMC-HVDC system for protection speed, but also has a good ability to distinguish lightning strikes. The main contributions of the paper are the following:

1. The characteristics of different faults and disturbances are detailed analyzed;

2. A protection method based on wavelet entropy for MMC-HVDC overhead transmission lines is proposed;

3. It is verified that the protection method is not affected by the distance of the fault, has a strong ability to withstand ground resistors, and has a strong noise tolerance.

The content of this paper from Sections $2-6$ is as follows: Section 2 analyzes the MMC-HVDC two-terminal transmission model in detail and introduces the fundamentals of the MMC-HVDC system and characteristics of the different faults. Section 3 explains the definition of wavelet entropy and the principles of wavelet entropy in describing spectrum features. Section 4 proposes the methods of transmission line protection. Section 5 shows the simulation results and verifies the effectiveness of the protection method based on wavelet entropy. Section 6 offers conclusions and discussions.

\section{Fault Characteristics of MMC-HVDC Transmission Lines}

\subsection{Fundamentals of MMC-HVDC System}

Limited by the compactness, lightness, and capital cost requirements of the converter station, the symmetrical monopole MMC-HVDC system has a good application prospect. Both domestic and many foreign MMC-HVDC projects have adopted symmetrical monopole converter stations [34,35]. The research in this paper is based on a symmetrical monopole MMC-HVDC system, as shown in Figure 1. The converter stations serve as an interface between DC and AC systems. The half-bridge SM is commonly used in recent MMC projects [36,37]. The work of this paper is based on half-bridge MMC, and the number of SMs of each bridge arm is $n$. The DC side of the converter is grounded through a large resistor $R_{g}$ and the neutral point is grounded. The bridge arm reactor $L_{0}$ can inhibit the interphase circulation current, reduce the bridge arm current's harmonic distortion rate, and suppress the fault current to protect equipment. $L_{m}$ is a current-limiting reactor, which can effectively reduce the rate of change of the fault current after the DC line fault and leave more time for the protection of the DC line and the action of the DC circuit breaker. The DC current $I_{d c}$ in the transmission line is measured at the point between the transmission line and the current-limiting reactor. In this paper, the transient states to be considered for protection include PPFs located at F1, PGFs, lightning disturbances (LDs), and lightning faults (LFs) located at F2, SMs short circuit faults (SMFs) on the arm of a phase located at F3, and single-phase grounding AC faults (AG-ACs) located at F4.

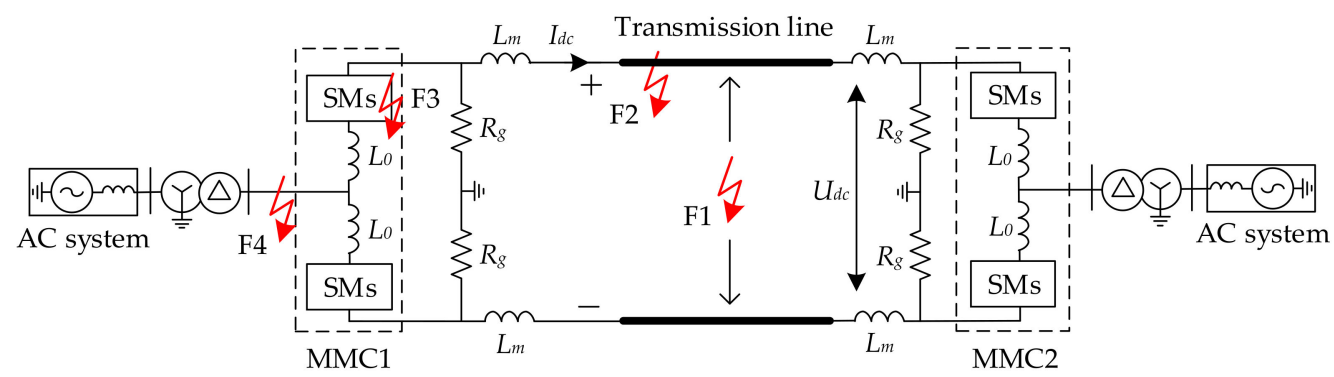

Figure 1. Diagram of a modular multilevel converter-based high-voltage direct current (MMC-HVDC).

Figure 2 shows the topology of a typical MMC converter, which has three identical phase units with six arms in total. Each arm consists of a reactor $L_{0}$ and $n$ SMs in series. 


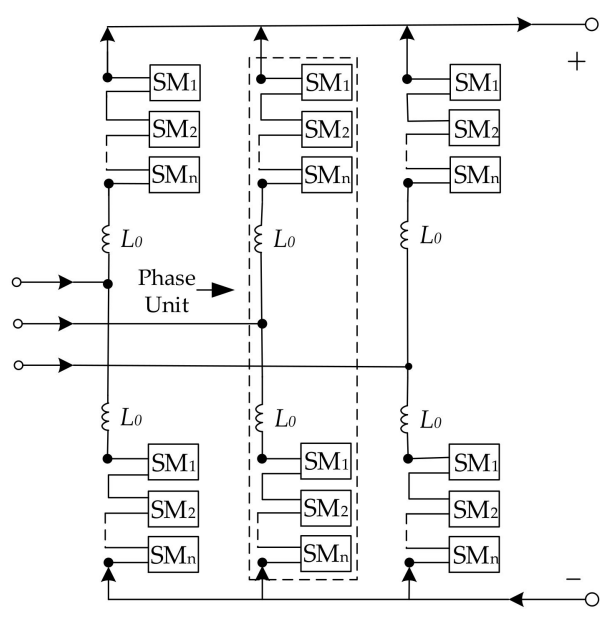

Figure 2. Topological structure of an MMC.

\subsection{Characteristics Analysis of PPF}

When a PPF occurs in an MMC-HVDC system, which is located at F1 in Figure 1, the fault process can be divided into three stages: the unblocked SM stage, the initial stage after the SM is blocked, and the steady stage after the SM is blocked. In order to detect a fault in a short time, it is necessary to use transient information at the beginning of the fault. Therefore, the fault transient process studied in this paper mainly focuses on the unblocked SM stage. The equivalent circuit of the unblocked SM stage is shown in Figure 3. The fault current $I_{d c}$ is mainly composed of the SM capacitor discharging current and AC source feeding the current. During this stage, SMs are switched to the normal operation mode, which means a total of $n$ SMs of each phase unit are in the on-state at any time to maintain the DC bus voltage. Due to the SM capacitance voltage balance control principle, SMs are switched on and off sequentially in a short time frame. All SMs in each phase can be divided into two groups, and discharge alternately, as shown in Figure 3b. Because of the high control frequency, it can be approximated that the two groups of SMs alternately discharged are in parallel in each phase. Therefore, it can be equivalent to a second order RLC discharging circuit, as shown in Figure 3c.

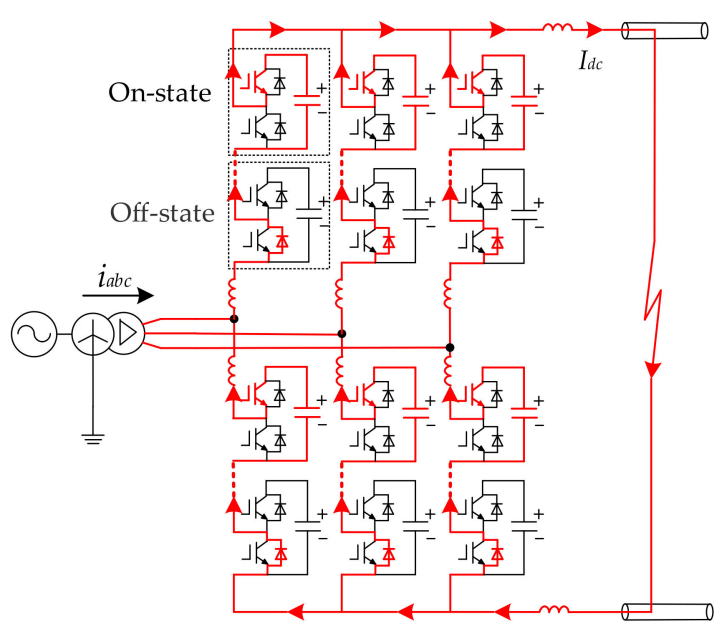

(a)

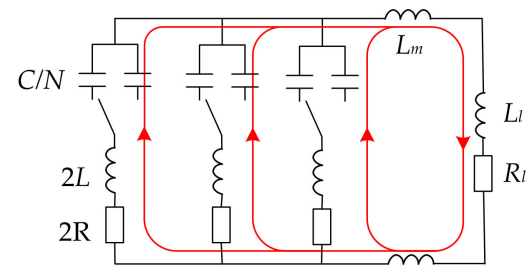

(b)

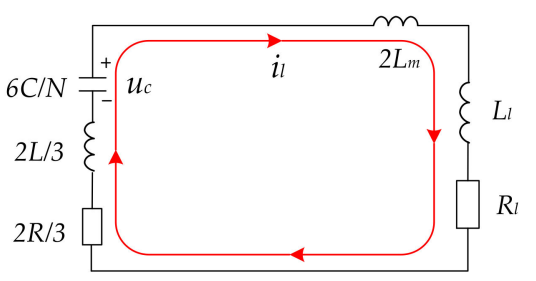

(c)

Figure 3. MMC-HVDC system pole-to-pole fault (PPF) circuit. (a) Detailed fault circuit; (b) equivalent fault circuit; (c) simplified fault circuit.

The waveform and frequency spectrum of fault current $I_{d c}$ is shown in Figure 4 . As shown in Figure 4a, the fault time is $0.01 \mathrm{~s}$, and the fault current rises to around $14 \mathrm{kA}$ after 
$10 \mathrm{~ms}$. A fast isolation is needed to avoid the large-amplitude fault currents. If DC circuit breakers are used, the post-fault transients of only a few microseconds will be recorded. The maximum breaking capacity of existing DC circuit breakers is $25 \mathrm{kA}$. According to the breaking capability and the operation time of the DC breaker, there is only a $3 \mathrm{~ms}$ transient signal after the fault is studied in this article. Due to the coupling between the two transmission lines, the Karenbauer phase mode transformation matrix is used to decouple the currents in both positive and negative poles. When compared with the ground mode component, the line mode component of currents is relatively stable. Its wave speed varies relatively little with the frequency and geographic environment of the corridor. Thus, the line mode component is adopted. The waveform of the current line mode component is shown in Figure 4b. As shown in Figure 4c, the line mode component of the fault current is used for spectrum analysis. It can be seen that the amplitude of the $0 \mathrm{~Hz}$ component exceeds $5 \mathrm{kA}$. The content of each frequency band gradually decreases with increasing frequency. There are obvious differences between the content of different frequencies, both in the low-frequency band and the intermediate frequency band. However, from around $20 \mathrm{kHz}$ to around $50 \mathrm{kHz}$, the frequency spectrum is evenly distributed and varies slightly.

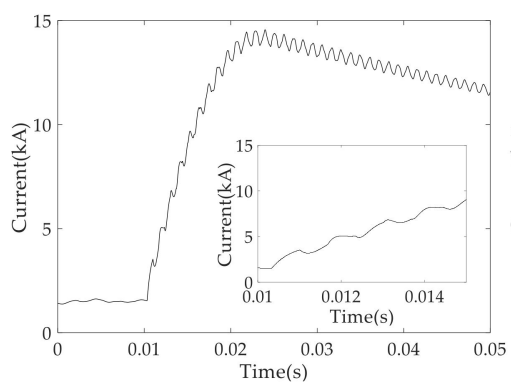

(a)

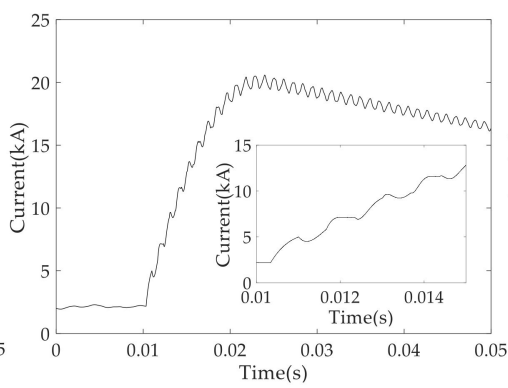

(b)

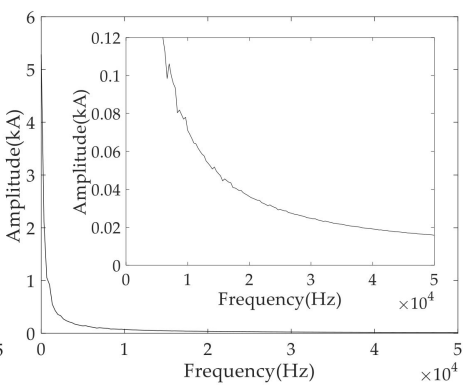

(c)

Figure 4. MMC-HVDC system PPF characteristics. (a) Current waveform; (b) current line mode component waveform; (c) spectrum analysis.

\subsection{Characteristics Analysis of PGF}

The characteristics of a PGF of MMC-HVDC are different from either traditional LCCbased HVDC converters or two-level VSC-based converters. When the PGF occurs at the location F2 in Figure 1, no closed loop can be formed between the faulted point and the SM capacitors. Only a slight transient signal is produced due to the deceasing bus potential of the faulted line. The capacitor will not discharge. Figure 5 illustrates the corresponding equivalent circuit. Therefore, the average SM capacitor voltage remains the same, and the DC voltage between two poles will be unchanged. The fault pole voltage becomes 0 . There is no steady-state fault current in the DC line.

The PGF transients also have wave processes similar to the PPF. The difference is that a PGF forms a fault loop with the earth, which causes the transient wave to be severely attenuated during propagation. This transient process can be equivalent to the result of switching an additional voltage source at the fault point. The equivalent additional source Eadd is:

$$
E_{\text {add }}(t)=-E_{\text {tra }}(t \geq 0),
$$

where $E_{\text {tra }}$ represents the transient voltage source that generates the transient current waveform. The transient characteristics of the PGF current $I_{d c}$ are shown in Figure 6 . The energy decreases with the increase in frequency. More sizeable differences can be found in the frequency band from $0 \mathrm{~Hz}$ to around $10 \mathrm{kHz}$ than the other bands. From around 10 to $50 \mathrm{kHz}$, the differences gradually decrease. 


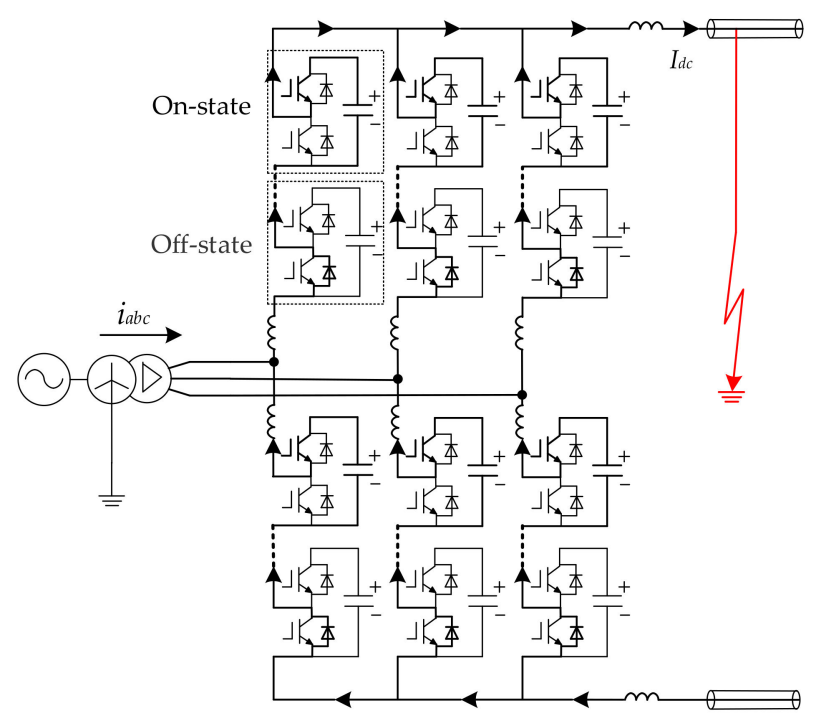

Figure 5. MMC-HVDC system pole-to-ground fault (PGF) circuit.

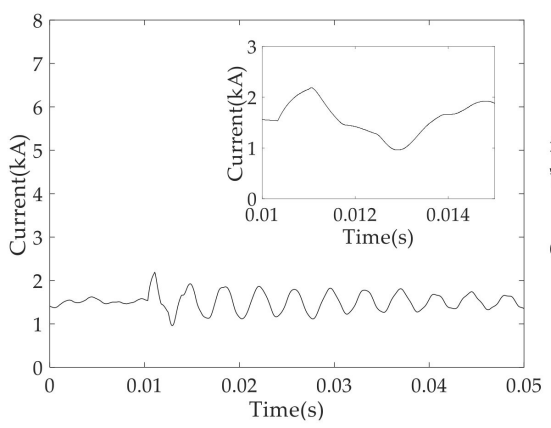

(a)

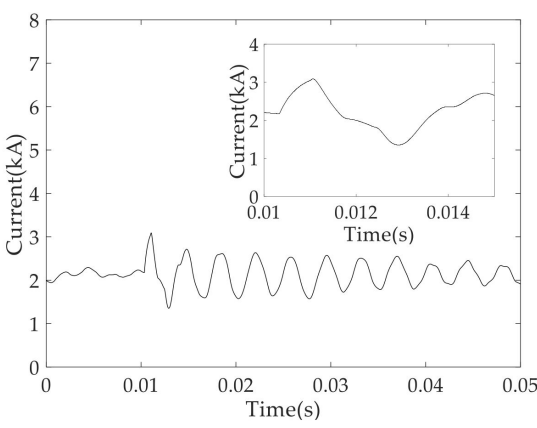

(b)

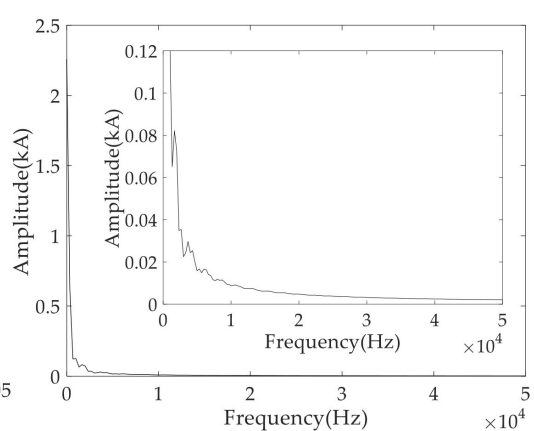

(c)

Figure 6. MMC-HVDC system PGF characteristics. (a) Current waveform; (b) current line mode component waveform; (c) spectrum analysis.

\subsection{Influence Caused by Lightning Strikes}

Lightning strikes are the main cause of transmission line protection misoperation. For the extremely short post fault transients of MMC-based protection, it is necessary to consider how to distinguish between faults and disturbances, especially LDs. Lightning waves generated by thunder are pulse transient waves, whose shape is mainly determined by its steepness and peak value. The double exponential wave is the equivalent calculation wave which is the closest to the actual lightning current wave, and is widely used in simulation analysis [38]. The generation of the transient waveform can be equivalent to superimposing an additional current source. The equation of the additional source $E_{\text {add }}$ is:

$$
E_{\text {add }}(t)=I_{0}\left(e^{-t / \alpha}-e^{-t / \beta}\right)(t \geq 0),
$$

Here, $I_{0}$ represents the amplitude of the lightning current; $\alpha$ and $\beta$ represent the correlation coefficients of the rise and fall of lightning current, respectively.

When an LD occurs, which is located at F2 in Figure 1, it can be equivalent to a single current source superimposed on the transmission line. The signal source is connected for a short time and generates high-frequency signals. The transient characteristics of an LD fault current $I_{d c}$ are shown in Figure 7. Most energy is contained in the lower frequency band, from $0 \mathrm{~Hz}$ to around $30 \mathrm{kHz}$, while only a small part of energy is included beyond $30 \mathrm{kHz}$. At the same time, large amplitude oscillations can be found in the frequency band 
below $15 \mathrm{kHz}$. Those harmonic energies cause the oscillating waveforms of lightning in the time domain.

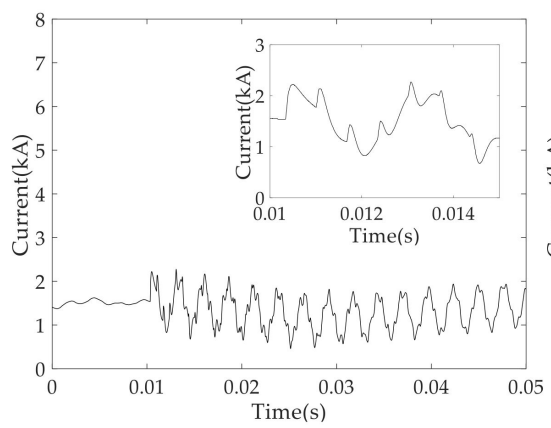

(a)

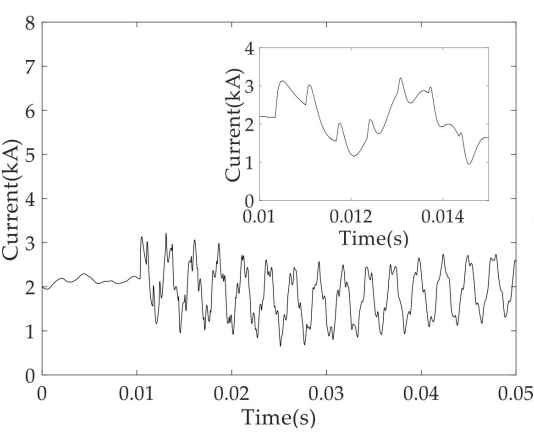

(b)

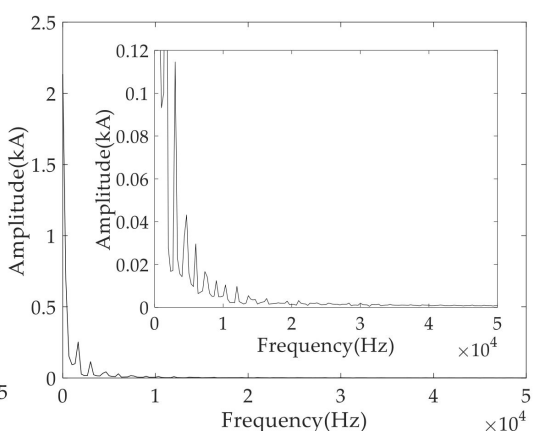

(c)

Figure 7. Transient characteristics of a lightning disturbance (LD). (a) Current waveform; (b) current line mode component waveform; (c) spectrum analysis.

When the lightning current amplitude is large, the voltage between the line and the tower might exceed the flashover voltage of the insulator. It is easy to cause an insulation breakdown, especially when the insulator is partially damaged, or flashover occurs along the surface. Then, it develops into a stable arc in a short time. The transmission line has a pole-to-ground fault through the tower, which is called a lightning fault (LF). According to its physical mechanism, the mathematical model of the additional source $E_{\text {add }}$ can be expressed as a piecewise function in Equation (3),

$$
E_{\text {add }}(t)=-E_{\text {tra }}\left(t_{0} \leq t \leq \infty\right) \text {, and } E_{\text {add }}(t)=I_{0}\left(e^{-t / \alpha}-e^{-t / \beta}\right)(0 \leq t \leq \infty),
$$

Here, $t_{0}$ is the moment of insulation breakdown, after which the LD evolves into an LF. The LF transient characteristics of $I_{d c}$ are shown in Figure 8. The frequency spectrum of LF looks similar to that of LD in Figure 7c. However, they are different. Due to the superposition of GF, whose energy is focused in the low-frequency band, the energy spectrum of LF reveals the features of both GF and LD. As demonstrated in Figure 8c, most energy is concentrated in the range from 0 to $30 \mathrm{kHz}$. The energy decreases gradually beyond $30 \mathrm{kHz}$. Although more harmonic-like energies are included in the frequency from around 15 to $50 \mathrm{kHz}$, less steepness is shown in LF than that in LD.

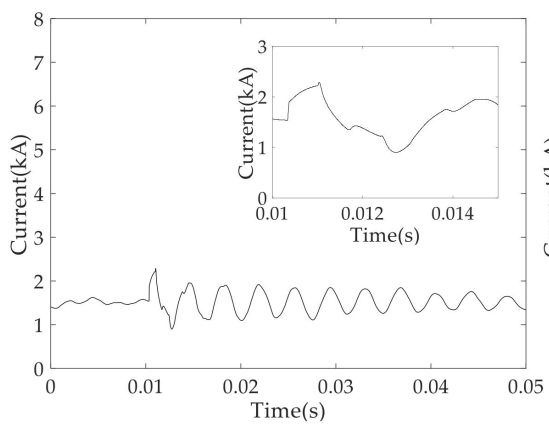

(a)

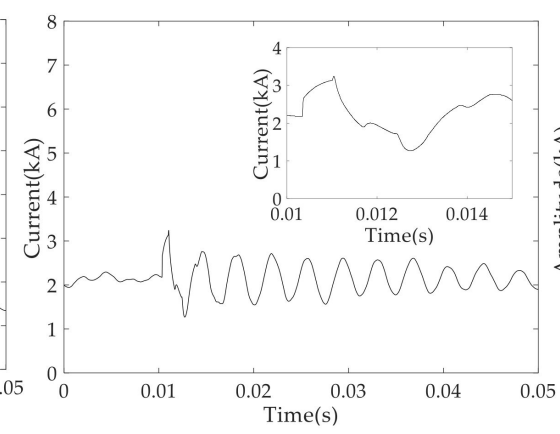

(b)

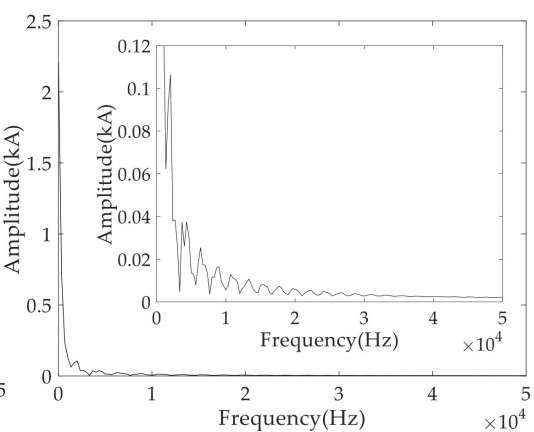

(c)

Figure 8. Transient characteristics of a lightning fault (LF). (a) Current waveform; (b) current line mode component waveform; (c) spectrum analysis.

\subsection{Characteristics Analysis of External Faults}

When an external fault occurs, line protection should not be activated. In MMC-HVDC systems, external faults mainly include valve faults and AC side faults. Among them, SMFs and AG-ACs are the most likely faults, respectively. For that reason, these two 
faults are considered in this paper: an SMF located at F3 and an AG-AC located at F4 in Figure 1. Figures 9 and 10 show the fault transient characteristics of $I_{d c}$ of the SMF and the AG-AC, respectively. For these two types of external faults, most of their energies are found between $0 \mathrm{~Hz}$ and around $5 \mathrm{kHz}$, but the energies attenuate greatly beyond $5 \mathrm{kHz}$.

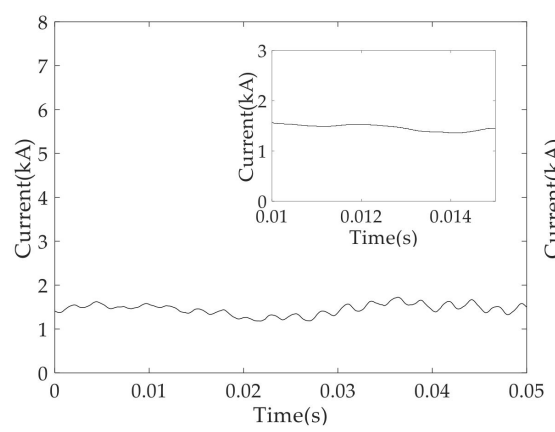

(a)

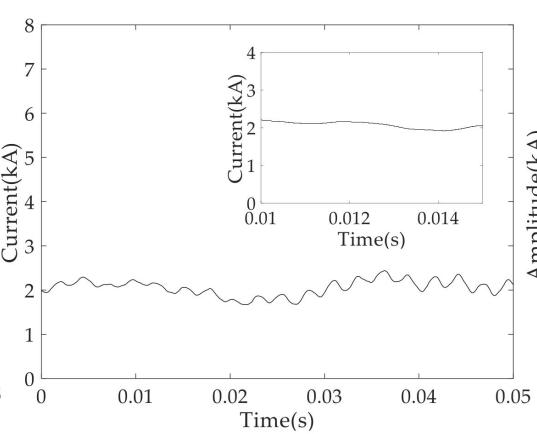

(b)

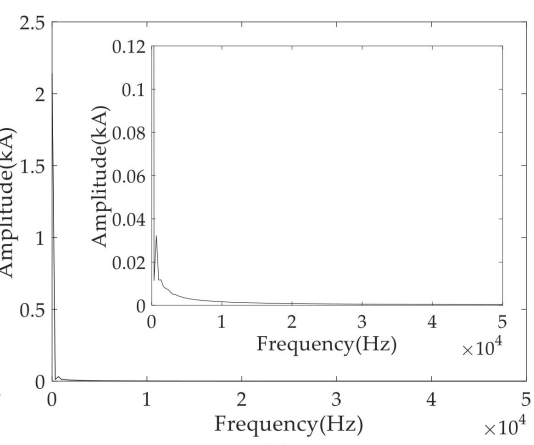

(c)

Figure 9. Fault characteristics of a sub-module short circuit fault (SMF) on the arm of a phase. (a) Current waveform; (b) current line mode component waveform; (c) spectrum analysis.

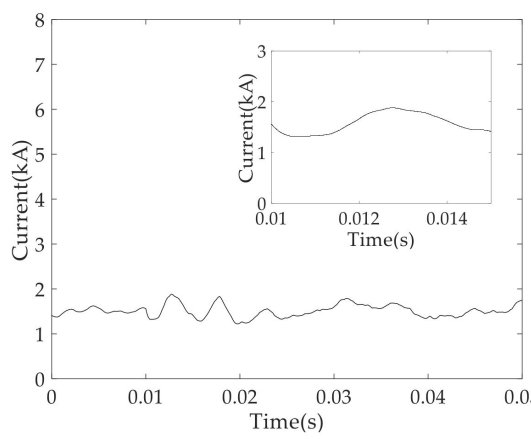

(a)

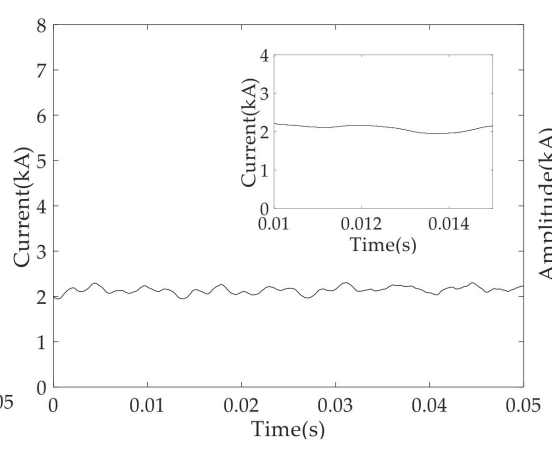

(b)

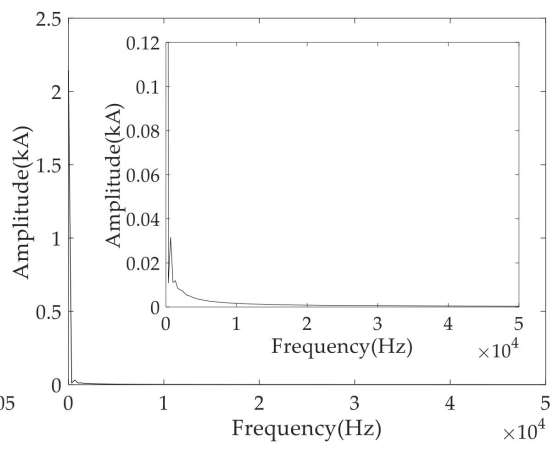

(c)

Figure 10. Fault characteristics of a single-phase grounding AC fault (AG-AC). (a) Current waveform; (b) current line mode component waveform; (c) spectrum analysis.

When an internal fault occurs, the transient current propagates from the fault point to both sides along the transmission line. Because the actual transmission line is basically a uniform line, which means that the resistor, inductance, and capacitance parameters are evenly distributed along the line, the high-frequency attenuations of the transient current at both ends of the line are not large. On the contrary, when an external fault occurs, the high-frequency component of the transient current attenuates significantly after passing through the boundary.

According to the analysis in this section, it can be found that different fault transients have different characteristics such as waveforms and frequency spectrum distributions. The high-frequency components of the transient current of the SMF and the AG-AC are obviously smaller than the ones of internal faults. The $0 \mathrm{~Hz}$ component of PPF is greater than those of PGF, LD, and LF. The spectra of PGF, LD, and LF in different frequency bands are obviously different, both the amplitude and the variations. If a reasonable signal processing and analyzing tool is used to describe these differences effectively and stably, various transients can be well separated, and the protection function can be realized.

\section{Wavelet Entropy Characterization of Spectrum Distribution}

\subsection{Definition of Wavelet Entropy}

Wavelet transform has good time-frequency localization performance $[27,28]$. It is considered as a "mathematical microscope", because it can "focus" the analysis object to 
any detail. Benefitting from the high sensitivity of the wavelets to the singularity and mutation of signals, wavelet transform is considered an effective signal processing method in multi-resolution analysis. Power system faults appear as sudden changes in voltage and current signals. Therefore, the use of a wavelet to detect the fault singularities is effective [29].

Entropy is one of the tools to measure the disorder degree of the whole system and it can also be regarded as a description of the degree of system uncertainty. If we regard a signal source as a material system, the more messages we may output and the more random and uncertain the signal source is, the more disordered and the greater the entropy is $[13,25]$.

Wavelet entropy can represent the change in signal complexity in the time domain, and also many features of signal in the frequency domain. Therefore, wavelet entropy has unique advantages in the representation of fault information of non-stationary timevarying signals. According to wavelet transform, the entire frequency band is divided into $m$ levels to obtain frequency bands of different levels. The wavelet coefficients in the $i$ th $(1 \leq i \leq m)$ frequency band form a set $X_{i}[39,40]$. Taking the maximum and minimum values of $X_{i}$ as upper and lower limits, respectively, this range is equally divided into $n$ intervals. The number of wavelet coefficients distributed in the $j$ th $(1 \leq j \leq n)$ interval is denoted as $x_{i j}$. Its probability is recorded as $p\left(x_{i j}\right)$, which is obtained by dividing the number of coefficients in different intervals by the total number of coefficients in this frequency band $X_{i}$. The formula of wavelet entropy $H_{i}$ of set $X_{i}$ is:

$$
H_{i}=-\sum p\left(x_{i j}\right) \log _{b}\left(x_{i j}\right)(j=1,2, \ldots, n),
$$

\subsection{Characterization of Frequency Spectrum by Wavelet Entropy}

In MMC-HVDC systems, to ensure protection speed and sensitivity, the sampling frequency of the protection device is required to be no less than $50 \mathrm{kHz}$; a short time window requires a high sampling frequency to increase the acquisition of transient information. In most engineering applications, the sampling frequency is set as $100 \mathrm{kHz}[17,18,20]$, and the largest is $1 \mathrm{MHz}$ [22]. In this work, we choose $200 \mathrm{kHz}$ as the sampling frequency. Then, the signal is decomposed by wavelet transform. Figure 11 shows the energy distribution of different wavelet frequency bands. Through spectrum analysis, there is a small amount of content of different frequencies from 50 to $100 \mathrm{kHz}$ of various faults, and the change is insignificant. Therefore, the spectrum display range is from 0 to $50 \mathrm{kHz}$ in this case. There are clear differences in the frequency spectrum of different faults in different frequency bands; in particular, the degrees of frequency fluctuation and disorder are different. For example, on the fourth level in the spectrum from $6250 \mathrm{~Hz}\left(200 \mathrm{kHz} / 2^{4+1}\right)$ to $12,500 \mathrm{~Hz}$ $\left(200 \mathrm{kHz} / 2^{4}\right)$, the differences between the content of different frequencies of lightning strikes are larger than the PGF. These characteristics can be characterized by entropy. 


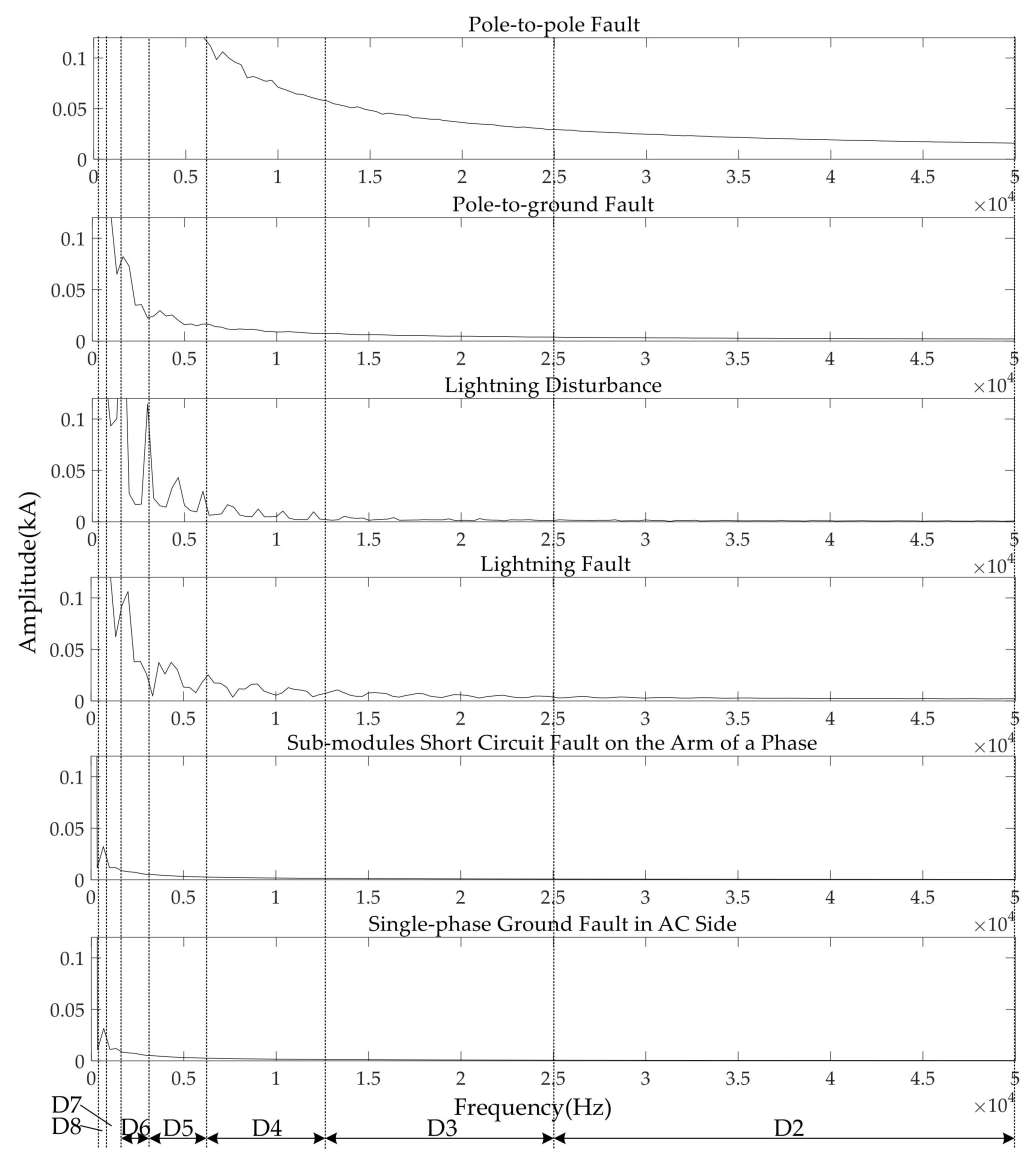

Figure 11. Spectrum analysis of different faults.

\subsection{Wavelet Entropy of Different Transients}

When using wavelet decomposition, the wavelet function and the number of decomposition levels need to be considered. The fourth Daubechies wavelet "db4" is used in the wavelet decomposition in this paper [41]. The number of wavelet decomposition levels should be less than nine levels [40]. Combined with the spectrum displayed in Figure 11, the number of decomposition levels is selected as eight. The wavelet entropy of different faults is shown in Figure 12.

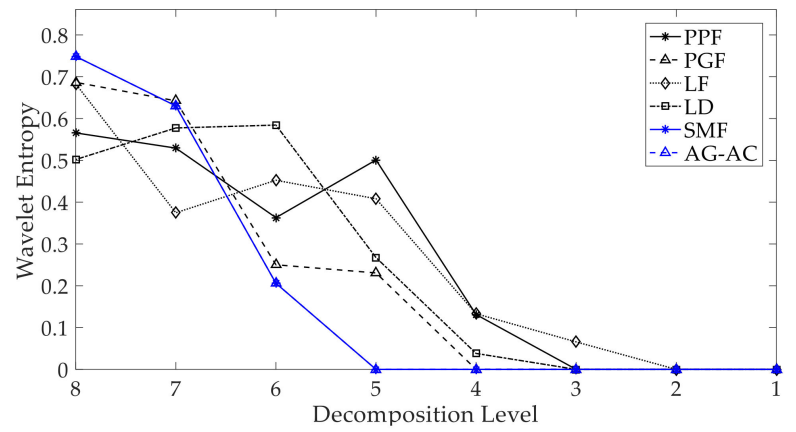

Figure 12. Wavelet entropies of different transients.

The wavelet entropy of each wavelet decomposition level indicates the degree of confusion of the detailed coefficients of the corresponding frequency band. From Figures 11 and 12, it can be seen that the amplitude and variation of the spectrum from $3125 \mathrm{~Hz}\left(200 \mathrm{kHz} / 2^{5+1}\right)$ to $50 \mathrm{kHz}\left(200 \mathrm{kHz} / 2^{2}\right)$ of SMF and AG-AC are small. The wavelet entropy of the 2nd to 5 th levels are all 0 . This means that after filtering by the boundary, from the fifth to the first level, the differences between the content of different frequencies are too small that the 
calculated entropy value is 0 . Its energy is mainly concentrated in the low-frequency band. The amplitude and change in the frequency spectrum of PGF are close to zero from $6250 \mathrm{~Hz}$ $\left(200 \mathrm{kHz} / 2^{4+1}\right)$ to $50 \mathrm{kHz}\left(200 \mathrm{kHz} / 2^{2}\right)$. The wavelet entropies of the 2 nd to 4 th levels are all 0 . This means that its transient signal energy and changes are mainly concentrated in the mid-frequency and low-frequency parts. From $12,500 \mathrm{~Hz}\left(200 \mathrm{kHz} / 2^{3+1}\right)$ to $50 \mathrm{kHz}$ $\left(200 \mathrm{kHz} / 2^{2}\right)$, the amplitude and change of the frequency spectrum of LD are also small. Its wavelet entropy of the 2nd to 3rd levels is 0 . Thus, its transient signal energy and changes are concentrated in the mid-frequency and high-frequency parts. The frequency spectrum of LF is close to zero from $25,000 \mathrm{~Hz}\left(200 \mathrm{kHz} / 2^{2+1}\right)$ to $50,000 \mathrm{~Hz}\left(200 \mathrm{kHz} / 2^{2}\right)$. Its wavelet entropy of the 2 nd is 0 . Its transient signal energy and changes still exist in the high-frequency part. The wavelet entropies of PPF, from the 4th to 8th levels, are relatively large. This indicates that the content of each frequency band changes uniformly.

Different transients have clear differences in wavelet entropy. Combined with the distribution of wavelet entropy, it is expected that the precise action of protection will be realized. Furthermore, the transient frequency spectrum is affected by many factors, and it is necessary to analyze the influence of different influencing factors on the wavelet entropy.

\subsection{Effect of Distance}

As transient signals are analyzed in this research, the effect of distance cannot be ignored. Longer transmission distance suggests greater attenuation which will lead to waveform distortion, as well as frequency spectrum variation. Reliable judgments are required for protection. To analyze the characterization of wavelet entropy for transient signals in different fault distances, the wavelet entropy of different fault distances is discussed.

Figure 13 shows the distribution of wavelet entropy when the internal fault occurs in different locations. The faults are located at 20,100, and $180 \mathrm{~km}$ along the line. As shown in Figure 13a, at different fault distances, the wavelet entropies of the 2nd to 4th levels are 0 . From the 6 th to 8 th level, the wavelet entropies have some fluctuations. In Figure $13 \mathrm{~b}$, from the 5 th to 8 th level, the wavelet entropies have some fluctuations, but they are larger than 0 and are different from external faults. In Figure 13c, the values of the 2nd to 3 rd levels are 0 , the entropy of each level changes insignificantly, and the overall trend is consistent. In Figure 13d, the values of the 3rd level are larger than zero and different from LDs. Fluctuations are mainly concentrated from levels 5 to 8 . Although the wavelet entropy changes under some decomposition levels, the overall distributions of wavelet entropy under different propagation distances are similar.

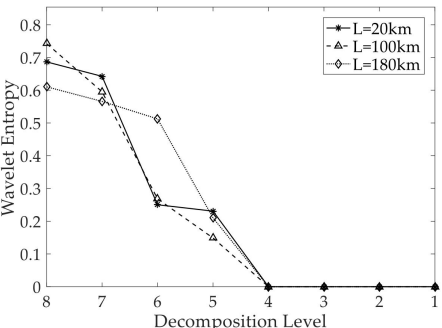

(a)

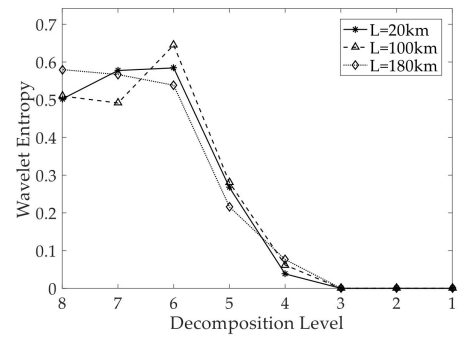

(c)

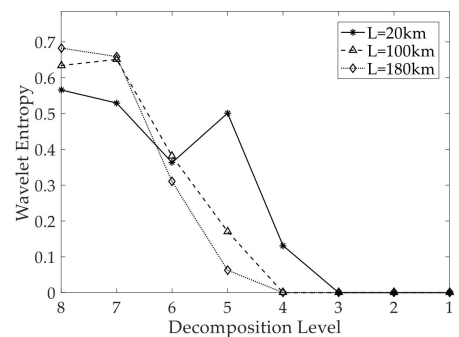

(b)

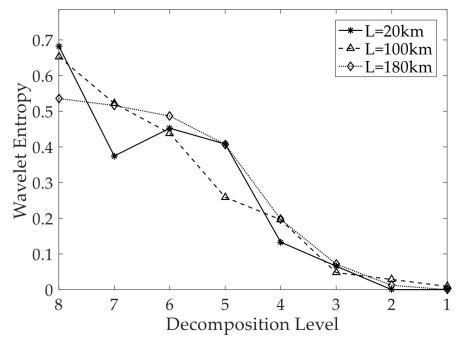

(d)

Figure 13. Effect of distance. (a) PGF; (b) PPF; (c) LD; (d) LF. 


\subsection{Effect of Ground Resistor}

The ground resistor affects the sensitivity of the protection. An excessively large ground resistor may make the transient characteristics of the fault unobvious and cause the protection to fail. Figure 14 shows the distribution of wavelet entropy when the internal fault occurs with different ground resistors. The resistances of the ground resistor studied in this section are $0.001,1$, and $50 \Omega$. They are located at $100 \mathrm{~km}$ of the overhead lines. Figure 14a shows entropies of PGF; the values of the 2nd to 4th levels are 0 . The trend of wavelet entropy changes is predominantly the same, and excessive resistor has little effect on the entropy. Figure 14b shows entropies of PPF; the values of the 5th level are larger than 0 , are different from the external faults, and all values fluctuates slightly. Figure $14 \mathrm{c}$ shows entropies of LF; the wavelet entropy of each level fluctuates slightly, but the trend is the same. The values of the 3 rd level are larger than 0 as well, and different from the LDs. Although the wavelet entropy has small numerical changes in some levels, the value has a small difference, and its overall distribution is the same.

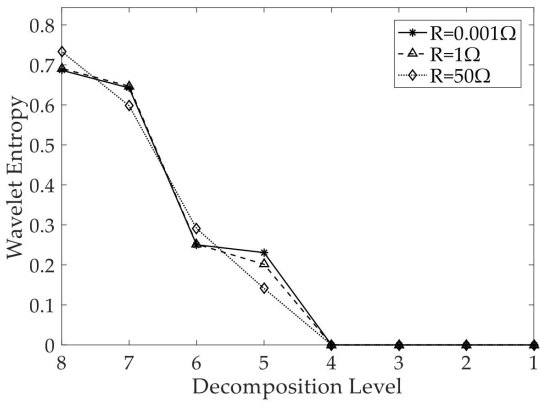

(a)

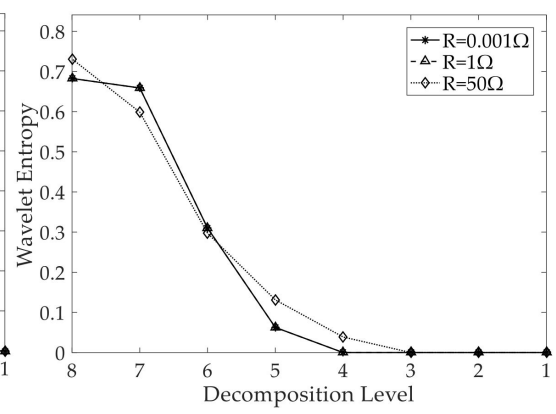

(b)

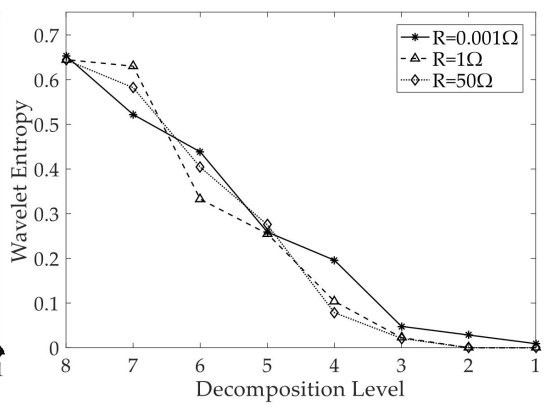

(c)

Figure 14. Effect of ground resistor. (a) PGF; (b) PPF; (c) LF

From the analysis, it can be seen that wavelet entropy is not affected by distance and a certain range of ground resistor.

As discussed in this section, different types of faults have different distributions of wavelet entropies. The 5th level wavelet entropies of the external faults such as SMFs and AG-ACs are 0 , while it is not zero for internal faults. The 4th level wavelet entropy of PGFs is 0 , which is different from that of LDs and LFs. The 3rd level wavelet entropy of LDs is 0. It is different from the 3rd level wavelet entropy of LFs. Therefore, through the comparison of wavelet entropies in certain decomposition levels, it is possible to identify internal faults, external faults, and the fault types.

\section{Methods of Transmission Line Protection}

\subsection{Starting Criterion}

The starting element contains one transient criterion and one substitute criterion. The specific starting criterion is

$$
|\Delta i|>0.1 I_{n} \text { or } i>1.1 I_{n}
$$

where $\Delta i$ is the change in positive current. It is calculated by subtracting the value of the instantaneous current $1 \mathrm{~ms}$ before. $i$ is the instantaneous current. $I_{n}$ is the current rating.

The purpose of setting the starting element is to enhance the reliability of the protection.

\subsection{Internal and External Fault Criterion}

According to the wavelet entropy distribution in Figure 13, the high-frequency energy of external transients is filtered and attenuated due to the existence of boundaries or discontinuous boundaries, such as current-limiting reactors, SM capacitances, bridge arm reactors, etc. According to the analysis in Section 3.3, the value of the 5th wavelet entropy 
can be used as a criterion for distinguishing internal and external faults. The fault criterion is set as

$$
\mathrm{W} 5=0,
$$

where W5 represents the wavelet entropy value of the 5 th level of the current line mode component during the fault. Therefore, if $\mathrm{W} 5=0$, it is considered as an external fault. Otherwise, it is determined as an internal fault.

\subsection{PPF Criterion}

Through the analysis in Section 2.2, in the initial stage of a PPF, there is a phenomenon of SM discharge. The fault current contains a large DC component. Through spectrum analysis, the fault current contains different frequency bands components with a large amplitude. The amplitude of the $0 \mathrm{~Hz}$ component can clearly distinguish the PPF. The fault criterion is set as

$$
\mathrm{A} 0>2.7 \mathrm{kA},
$$

where $\mathrm{A} 0$ is the amplitude of the $0 \mathrm{~Hz}$ component. Through a large number of simulation experiments, the setting value is $2.7 \mathrm{kA}$. Therefore, if $\mathrm{A} 0>2.7 \mathrm{kA}$, it is considered as a PPF. Otherwise, it is considered as another fault.

\subsection{Recognition Method for PGF, LD, and LF}

Combined with the analysis in Section 3, the spectrum distributions of PGF, LD, and LF have clear differences from $6250 \mathrm{~Hz}\left(200 \mathrm{kHz} / 2^{4+1}\right)$ to $25,000 \mathrm{~Hz}\left(200 \mathrm{kHz} / 2^{2+1}\right)$. Therefore, the wavelet entropy values of the $3 \mathrm{rd}$ to 4 th levels have distinguished differences accordingly. This paper takes the value of the 4 th level of wavelet entropy as the criterion of PGF. The fault criterion is set as

$$
\mathrm{W} 4=0,
$$

where W4 represents the wavelet entropy value of the 4 th level of the current line mode component during the fault. Therefore, if $\mathrm{W} 4=0$, it is considered as a PGF. Otherwise, it is considered as a lightning strike.

According to the previous analysis, this paper adopts the value of the 3rd level of wavelet entropy as the criterion for the LD. The fault criterion is set as,

$$
\mathrm{W} 3=0,
$$

where W3 represents the wavelet entropy value of the 3rd level of the current line mode component during the fault. If $\mathrm{W} 3=0$, it is considered as an LD. Otherwise, it is considered as an LF.

\subsection{Flow Chart of Protection Plan}

Combined with the above analysis, the protection scheme is designed as shown in Figure 15. Firstly, the current value is detected to determine whether the protection system is activated or not. Then, the wavelet entropy of the line mode component is calculated and used to determine its fault zone based on the internal and external fault criterion. If it is an internal fault, the fault will be judged according to the PPF criterion, PGF criterion, and LD criterion in turn. Finally, the fault type is given. 


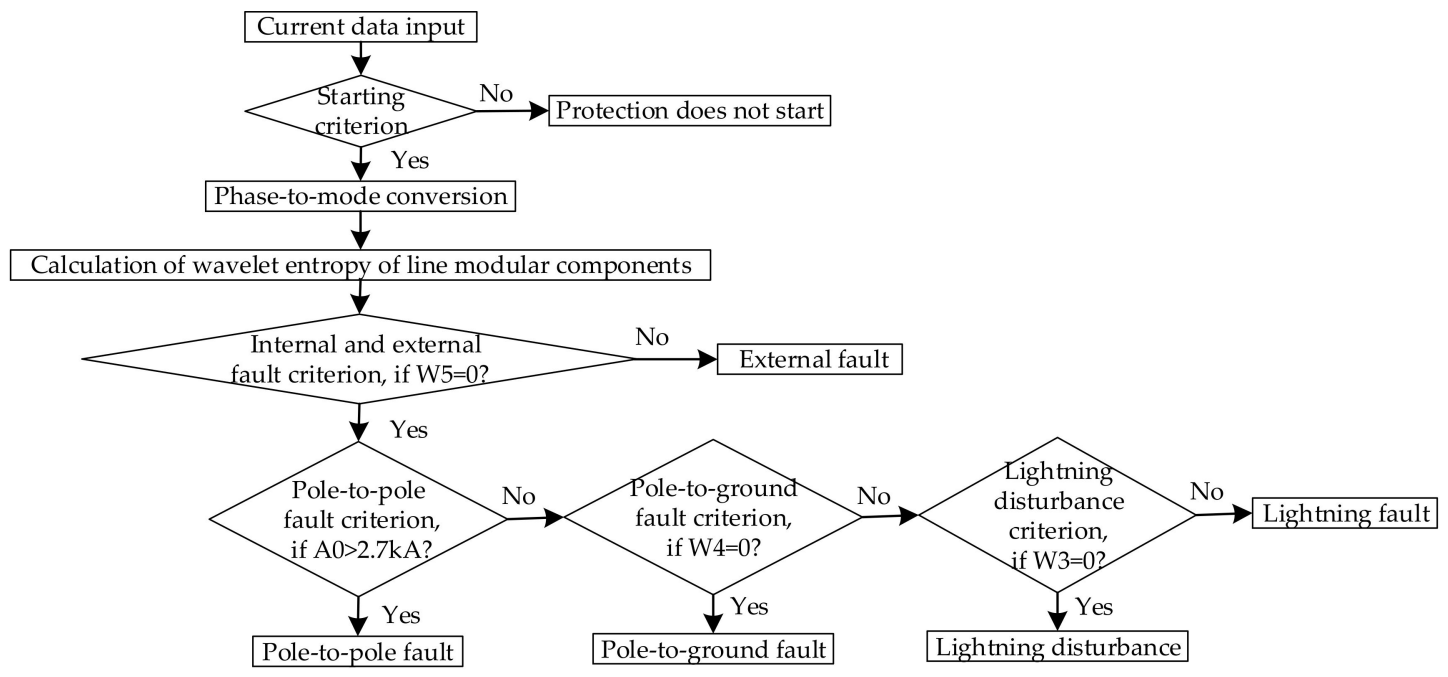

Figure 15. Flowchart of the protection plan.

\section{Simulation and Discussion}

A two-terminal MMC-HVDC system is modeled on the PSCAD platform, and the topology is as shown in Figure 1. The overhead transmission line model in PSCAD is applied. The line model is shown in Appendix A. The system parameters are show in Table 1.

Table 1. The parameters of the system.

\begin{tabular}{cccc}
\hline Transmission line length & $200 \mathrm{~km}$ & Transmission capacity & $1000 \mathrm{MW}$ \\
\hline AC voltage & $220 \mathrm{kV}$ & DC bus voltage & $\pm 320 \mathrm{kV}$ \\
\hline Inductance of the smoothing reactor & $50 \mathrm{mH}$ & Inductance of the arm reactor & $200 \mathrm{mH}$ \\
\hline Number of SMs of each bridge arm & 12 & SM capacitance & $360 \mu \mathrm{F}$ \\
\hline
\end{tabular}

This section simulates PPF, PGF, LF, FD, SMF, and AG-AC, with different parameters. The locations of those faults are demonstrated in Figure 1. Among them, the ground resistors are from 0.001 to $50 \Omega$. The distance to the fault location is from 0 to $200 \mathrm{~km}$. The number of short-circuit modules of the SMF varies from 1 to 12 . When the LF occurs, the lightning current amplitude ranges from 25 to $50 \mathrm{kA}$. When the LD occurs, the lightning current amplitude ranges from 5 to $30 \mathrm{kA}$. The details of simulation parameters are listed in Table 2.

Table 2. Experiment in different scenarios.

\begin{tabular}{ccccc}
\hline Type & $\begin{array}{c}\text { Ground Resistor } \\
(\boldsymbol{\Omega}) / \text { No. of Fault SMs }\end{array}$ & Fault Distance $\mathbf{( k m )}$ & $\begin{array}{c}\text { Amplitude of } \\
\text { Lightning Strikes (kA) }\end{array}$ & No. of Faults \\
\hline \multirow{2}{*}{ PPF } & $0.001,0.1,1,10,50$ & $\begin{array}{c}10,20,30,40,50,60,70,80,90,100,110,120, \\
130,140,150,160,170,180,190,200\end{array}$ & N/A & 100 \\
\hline \multirow{2}{*}{ PGF } & $0.001,0.1,1,10,50$ & $\begin{array}{c}10,20,30,40,50,60,70,80,90,100,110,120, \\
130,140,150,160,170,180,190,200\end{array}$ & N/A & 100 \\
\hline \multirow{2}{*}{ LD } & N/A & $\begin{array}{c}10,20,30,40,50,60,70,80,90,100,110,120, \\
130,140,150,160,170,180,190,200\end{array}$ & $5,10,20,30$ \\
\hline
\end{tabular}


Table 2. Cont.

\begin{tabular}{|c|c|c|c|c|}
\hline Type & $\begin{array}{l}\text { Ground Resistor } \\
(\Omega) / \text { No. of Fault SMs }\end{array}$ & Fault Distance (km) & $\begin{array}{c}\text { Amplitude of } \\
\text { Lightning Strikes (kA) }\end{array}$ & No. of Faults \\
\hline LF & $0.001,0.1,1,10,50$ & $\begin{array}{c}10,20,30,40,50,60,70,80,90,100,110,120 \\
130,140,150,160,170,180,190,200\end{array}$ & $25,30,40,50$ & 400 \\
\hline SMF & $\begin{array}{c}1,2,3,4,5,6,7,8,9,10 \\
11,12 \\
\text { (Six bridge arms) }\end{array}$ & $\mathrm{N} / \mathrm{A}$ & $\mathrm{N} / \mathrm{A}$ & 72 \\
\hline AG-AC & $\begin{array}{l}0.001,0.1,1,10,50 \\
\text { (Three phases) }\end{array}$ & $\mathrm{N} / \mathrm{A}$ & $\mathrm{N} / \mathrm{A}$ & 15 \\
\hline
\end{tabular}

\subsection{Protection Operation Results of Different Faults}

Using the simulated MMC-based transmission model and simulated faults with parameters in Table 2, the protection operations of the proposed method are tested with different types of faults. The protection operation results are shown in Table 3.

Table 3. Results for different fault types with wavelet entropy.

\begin{tabular}{ccccccc}
\hline Type & W5 & $\begin{array}{c}\text { Amplitude } \\
(\mathbf{0 ~ H z})\end{array}$ & W4 & W3 & Result & Accuracy \\
\hline PPF & $>0$ & $>2.7 \mathrm{kA}$ & - & - & $100(\mathrm{PPF})$ & $100 \%$ \\
\hline PGF & $>0$ & $<2.7 \mathrm{kA}$ & $=0$ & - & $100(\mathrm{PGF})$ & $100 \%$ \\
\hline $\mathrm{LD}$ & $>0$ & $<2.7 \mathrm{kA}$ & $>0$ & $=0$ & $80(\mathrm{LD})$ & $100 \%$ \\
\hline $\mathrm{LF}$ & $>0$ & $<2.7 \mathrm{kA}$ & $>0$ & $>0$ & $400(\mathrm{LF})$ & $100 \%$ \\
\hline SMF & $=0$ & $\mathrm{~N} / \mathrm{A}$ & $\mathrm{N} / \mathrm{A}$ & $\mathrm{N} / \mathrm{A}$ & $72(\mathrm{SMF})$ & $100 \%$ \\
\hline AG-AC & $=0$ & $\mathrm{~N} / \mathrm{A}$ & $\mathrm{N} / \mathrm{A}$ & $\mathrm{N} / \mathrm{A}$ & $\begin{array}{c}15 \\
(\mathrm{AG}-\mathrm{AC})\end{array}$ & $100 \%$ \\
\hline
\end{tabular}

As shown in Table 3, the proposed protection method can effectively discriminate internal and external faults, and it can also recognize the internal transient type. No misoperations are generated by the wavelet entropy-based method. This method is effective in protecting non-faulted parts and finding faulted ones.

\subsection{Effect of Number of Faulted SMs}

The number of faulted SMs will affect the value and change of the short circuit current in DC transmission lines. It is necessary to study the effect of the number of fault SMs. Here, the performance of the proposed protection method is discussed as the number of fault SMs ranges from 1 to 12 . The 5 th level wavelet entropy W5 of fault current $I_{d c}$ is always 0 , which is obviously different from the case of an internal fault. It meets the internal and external fault criterion and is judged to be an external fault. As shown in Figure 16, the accuracy of the protection actions of different kinds of faults are all $100 \%$, no matter how many SMs are faulted. Here, $\mathrm{AP}, \mathrm{AN}, \mathrm{BP}, \mathrm{BN}, \mathrm{CP}$, and $\mathrm{CN}$ represent the upper (positive) and lower (negative) bridge arms of the $A B C$ three-phase in the MMC converter, respectively. The change in the number of fault SMs will not affect the action of the protection criterion. 


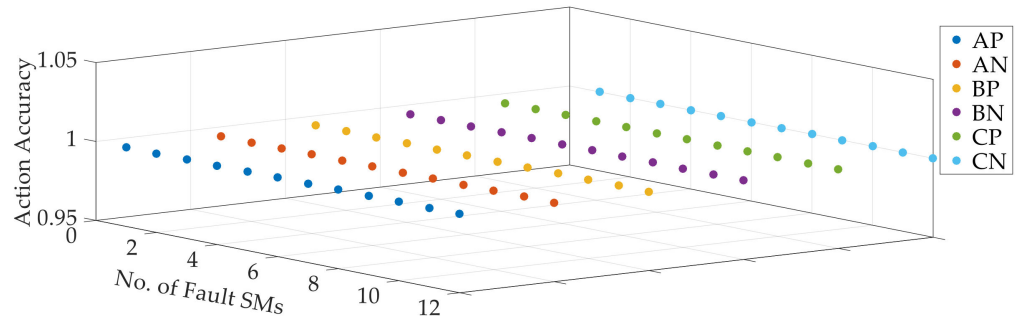

Figure 16. The influence of number of faulted SMs on the action accuracy.

\subsection{Effect of Ground Resistor}

A different ground resistor has an effect on the magnitude of transient signals, which will affect the accuracy of the protection actions. Here, the performance of the proposed method in dealing with PPF, PGF, LF, and AG-AC is discussed. Figure 17 shows the influence of the ground resistor on the action accuracy. As demonstrated by Figure 17, when the ground resistor is smaller than $50 \Omega$, the proposed method is immune to the change in ground resistor. However, with the increase in ground resistor, the fluctuation of high-frequency components of the transient currents becomes less obvious, which mean less disorder in high-frequency bands, and decreases. For internal faults, the values of W4 and W3 will decrease, and misoperations of protection will be found. However, for external faults, such as AG-AC, the criterion W5 $=0$ is not affected. The judgment of external faults is still effective.

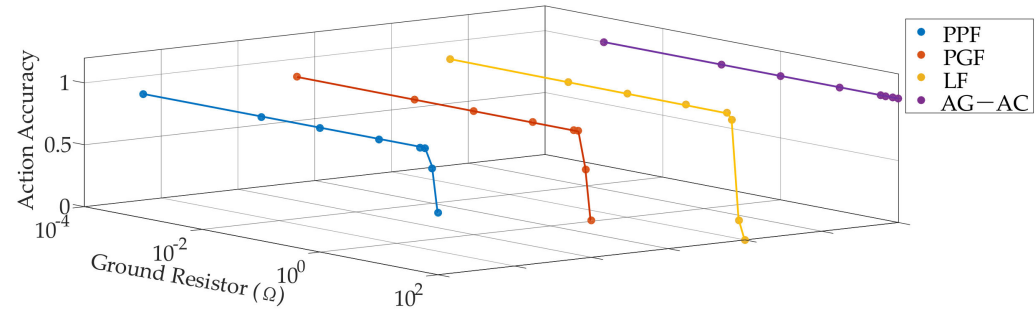

Figure 17. The influence of ground resistor on the action accuracy.

\subsection{Effect of Fault Distance}

The fault distance will affect the sensitivity of the protection scheme. It is necessary to study the effect of different fault distances for PPF, PGF, LD, and LF in this work. The action accuracy of the protection scheme when different faults occur at different positions is shown in Figure 18. When internal faults occur at different distances, the inequality W5 $>0$ is always true. Under different internal faults, the values of A0, W4, and W3 are respectively in accordance with different fault type criterions. The fault types can be distinguished effectively without being affected by the fault distance. The results show the proposed wavelet entropy-based method is immune to the variation of fault distance.

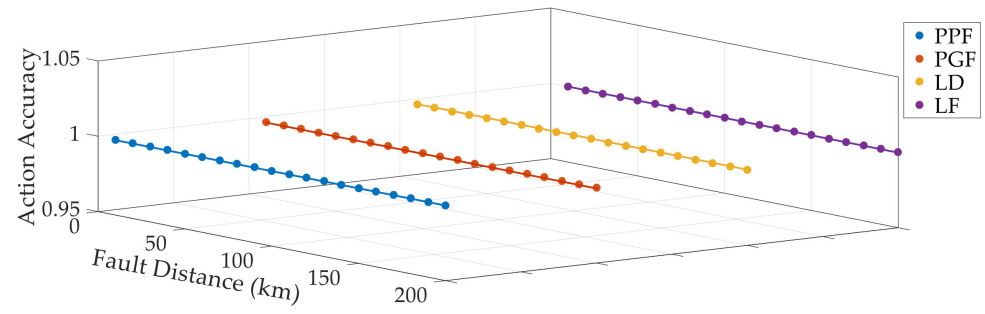

Figure 18. The influence of fault distance on the action accuracy.

\subsection{Effect of Signal-To-Noise Ratio (SNR)}

Noise interference is usually encountered in the practical environment. The influence of Gaussian white noise with different power on the protection is studied. The accuracy of 
the actions of the protection system under the influence of SNR is shown in Figure 19. As the Gaussian white noise will pollute the high frequency components of transients and the 5th level wavelet entropy will increase accordingly, the external faults will be judged to be internal ones. The noise tolerance of the internal and external fault criterion is only $60 \mathrm{~dB}$. For internal faults recognition, the noise tolerance of the PPF criterion is $30 \mathrm{~dB}$. It has good noise tolerance. The noise tolerance of the PGF criterion is $45 \mathrm{~dB}$. When the noise reaches $30 \mathrm{~dB}$, it will have a misjudgment rate up to $25 \%$. The noise tolerance of the LD criterion and LF criterion is $30 \mathrm{~dB}$. This means the protection method can effectively distinguish faults from disturbances even when the signal is seriously polluted.

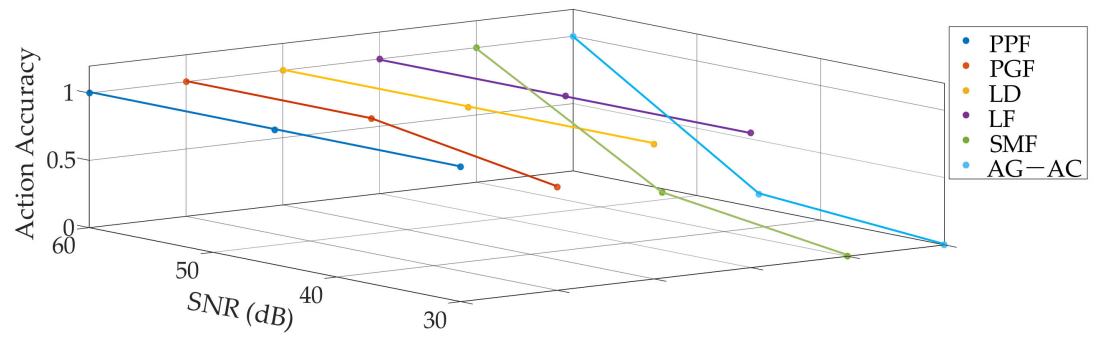

Figure 19. The influence of signal-to-noise (SNR) on the action accuracy.

From the above analysis, the proposed protection scheme is proved to be feasible in the absence of noise. The protection method can accurately distinguish the transient type under different scenarios, such as different ground resistors, different fault distances, different numbers of faulted SMs, and different SNRs. These results demonstrate the proposed wavelet entropy-based method can distinguish faults from interferences with high accuracy and reduce the misjudgments of protections.

\section{Conclusions}

A wavelet entropy-based protection method is proposed for symmetrical monopole MMC-HVDC overhead lines in this paper. Firstly, the fault characteristics of PPF, PGF, LD, LF, SMF, and AG-AC are analyzed in detail. Then, the definition of wavelet entropy is introduced and the wavelet entropy of different waveforms is analyzed. According to the different wavelet entropy values, the corresponding protection method is designed. Finally, theoretical analysis, simulation results generated by PSCAD/EMTDC, and discussions on the influence of different factors on the proposed protection method demonstrate that this method can not only accurately identify internal faults and external faults, but also effectively distinguish PPF, PGF, LD, and LF. At the same time, the method has strong adaptability and good noise tolerance in different fault locations and different fault ground resistors.

For systems with similar topologies, where same transient post-fault procedure can be produced, the proposed protection method can be used directly. However, for some other HVDC systems, such as asymmetrical monopole transmission system or bipolar asymmetrical transmission systems, the transient characteristics are different. The settings or criterions of the proposed wavelet-entropy-based protection method should be adjusted according to the spectrum distributions of different transients.

The research in this article is not to deny the application of traditional protection methods in MMC-HVDC, but to provide a new idea and perspective. Future work can focus more on improving the noise tolerance of the protection or introduce artificial intelligence methods to classify the characteristics of different faults.

Author Contributions: W.H. wrote the paper; G.L. developed the method; M.C. performed the experiments; J.H. provided some suggestions to improve this paper; Z.L. helped improve the expression of this paper; Y.Z. helped improve the performance of the algorithm. All authors have read and agreed to the published version of the manuscript. 
Funding: This research was funded by the National Key R\&D Program of China, grant number 2018YFB0904600.

Institutional Review Board Statement: Not applicable.

Informed Consent Statement: Not applicable.

Data Availability Statement: The data presented in this study are available on request from the corresponding author. The data are not publicly available due to privacy.

Acknowledgments: This research is funded by the National Key R\&D Program of China (No. 2018YFB0904600).

Conflicts of Interest: The authors declare no conflict of interest.

\section{Appendix A}

The line model of overhead lines is shown in Figure A1. The tower data of the MMC-HVDC transmission line are shown in Figure A2.

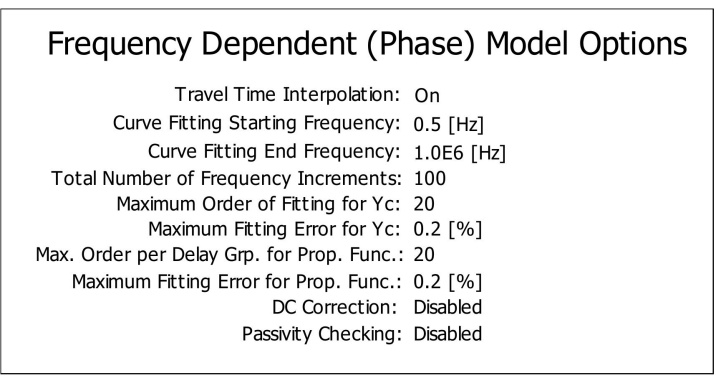

Figure A1. Line model of overhead lines.
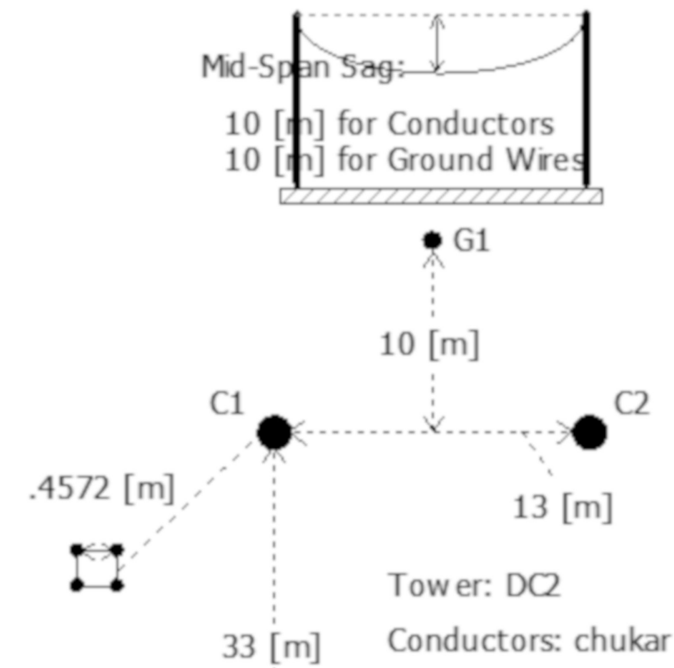

Ground_Wires: 1/2_HighStrengthSteel

$0[\mathrm{~m}]$

$\cdots$

Resistivity: $100.0[\mathrm{ohm} * \mathrm{~m}]$
Aerial: Analytical Approximation (Deri-Semlyen)
$\begin{gathered}\text { Underground: Direct Numerical Int egration } \\ \text { Mutual: Analytical Approximation (Lucca) }\end{gathered}$

Figure A2. Tower data of the MMC-HVDC transmission line. 


\section{References}

1. Kamran, S.; Lennart, H.; Hans-Peter, N.; Staffan, N.; Remus, T. Control and protection of MMC-HVDC under AC and DC network fault contingencies. In Design, Control, and Application of Modular Multilevel Converters for HVDC Transmission Systems; IEEE: Piscataway, NJ, USA, 2016; pp. 318-335.

2. Ning, L.; Zheng, X.; Tai, N.; Huang, W.; Chen, J.; Wu, Z. A novel pilot protection scheme for MMC-HVDC transmission lines. In Proceedings of the 2017 IEEE Energy Conversion Congress and Exposition (ECCE), Cincinnati, OH, USA, 1-5 October 2017; pp. 105-110.

3. Sneath, J.; Rajapakse, A.D. DC fault protection of a nine-terminal MMC HVDC grid. In Proceedings of the 11th IET International Conference on AC and DC Power Transmission, Birmingham, UK, 10-12 February 2015; pp. 1-8.

4. Cai, L.; Karaagac, U.; Mahseredjian, J. Simulation of startup sequence of an offshore wind farm With MMC-HVDC grid connection. IEEE Trans. Power Deliv. 2017, 32, 638-646. [CrossRef]

5. Karaagac, U.; Mahseredjian, J.; Cai, L.; Saad, H. Offshore wind farm modeling accuracy and efficiency in MMC-based multiterminal HVDC connection. IEEE Trans. Power Deliv. 2017, 32, 617-627. [CrossRef]

6. Bertilson, K.; Alishah, S.R.; Hosseini, H.S.; Babaei, E.; Aalami, M.; Ali, S.M.J.; Gharehpetian, B.G. A new generalized cascade multilevel converter topology and its improved modulation technique. Int. J. Circ. Theor. Appl. 2020. [CrossRef]

7. Daryabak, M.; Filizadeh, S.; Jatskevich, J.; Davoudi, A.; Saeedifard, M.; Sood, V.K.; Martinez, J.A.; Aliprantis, D.; Cano, J.; Mehrizi-Sani, A. Modeling of LCC-HVDC systems using dynamic phasors. IEEE Trans. Power Deliv. 2014, 29, $1989-1998$. [CrossRef]

8. Wu, J.; Li, H.; Wang, G.; Liang, Y. An improved traveling-wave protection scheme for LCC-HVDC transmission lines. IEEE Trans. Power Deliv. 2017, 32, 106-116. [CrossRef]

9. Belda, N.A.; Plet, C.A.; Smeets, R.P.P. Analysis of faults in multiterminal HVDC grid for definition of test requirements of HVDC circuit breakers. IEEE Trans. Power Deliv. 2018, 33, 403-411. [CrossRef]

10. Bucher, M.K.; Franck, C.M. Contribution of fault current sources in multiterminal HVDC cable networks. IEEE Trans. Power Deliv. 2013, 28, 1796-1803. [CrossRef]

11. Wen, W.; Huang, Y.; Sun, Y.; Wu, J.; Al-Dweikat, M.; Liu, W. Research on current commutation measures for hybrid DC circuit breakers. IEEE Trans. Power Deliv. 2016, 31, 1456-1463. [CrossRef]

12. Franck, C.M. HVDC circuit breakers: A review identifying future research needs. IEEE Trans. Power Deliv. 2011, 26, 998-1007. [CrossRef]

13. Kerf, D.K.; Srivastava, K.; Reza, M.; Bekaert, D.; Cole, S.; van Hertem, D.; Belmans, R. Wavelet-based protection strategy for DC faults in multi-terminal VSC HVDC systems. IET Gener. Transm. Distrib. 2011, 5, 496-503. [CrossRef]

14. Liu, X.; Osman, A.H.; Malik, O.P. Hybrid traveling wave/boundary protection for monopolar HVDC line. IEEE Trans. Power Deliv. 2009, 24, 569-578. [CrossRef]

15. Zhang, Y.; Tai, N.; Xu, B. Fault analysis and traveling-wave protection scheme for bipolar HVDC lines. IEEE Trans. Power Deliv. 2012, 27, 1583-1591. [CrossRef]

16. Suonan, J.; Gao, S.; Song, G.; Jiao, Z.; Kang, X. A novel fault-location method for HVDC transmission lines. IEEE Trans. Power Deliv. 2010, 25, 1203-1209. [CrossRef]

17. Ikhide, M.; Tennakoon, S.; Griffiths, A.; Subramanian, S.; Ha, H. Fault detection in Multi-Terminal Modular Multilevel Converter (MMC) based High Voltage DC (HVDC) transmission system. In Proceedings of the 2015 50th International Universities Power Engineering Conference (UPEC), Piscataway, NJ, USA, 1-4 September 2015; pp. 1-6.

18. Leterme, W.; Beerten, J.; Hertem, D.V. Nonunit protection of HVDC grids with inductive DC cable termination. IEEE Trans. Power Deliv. 2016, 31, 820-828. [CrossRef]

19. Tzelepis, D.; Dyśko, A.; Fusiek, G.; Nelson, J.; Niewczas, P.; Vozikis, D.; Orr, P.; Gordon, N.; Booth, D.C. Single-ended differential protection in MTDC networks using optical sensors. IEEE Trans. Power Deliv. 2017, 32, 1605-1615.

20. Samir, A.; Abu-Elanien, A.E.B.; Abdel-Khalik, A.S.; Massoud, A.M.; Ahmed, S. A directional protection technique for MTDC networks. In Proceedings of the 2015 4th International Conference on Electric Power and Energy Conversion Systems (EPECS), Sharjah, United Arab Emirates, 24-26 November 2015; pp. 1-6.

21. Song, G.; Hou, J.; Guo, B.; Chen, Z. Pilot protection of hybrid MMC DC grid based on active detection. Prot. Control. Mod. Power Syst. 2020, 5, 6. [CrossRef]

22. Li, Y.; Gong, Y.; Jiang, B. A novel traveling-wave-based directional protection scheme for MTDC grid with inductive DC terminal. Electr. Power Syst. Res. 2018, 157, 83-92. [CrossRef]

23. He, J.; Chen, K.; Li, M.; Luo, Y.; Liang, C.; Xu, Y. Review of protection and fault handling for a flexible DC grid. Prot. Control. Mod. Power Syst. 2020, 5, 15. [CrossRef]

24. Li, B.; He, J.; Li, Y.; Li, B. A review of the protection for the multi-terminal VSC-HVDC grid. Prot. Control. Mod. Power Syst. 2019, 4, 21. [CrossRef]

25. Gaouda, A.M.; El-Saadany, E.F.; Salama, M.M.A.; Sood, V.K.; Chikhani, A.Y. Monitoring HVDC systems using wavelet multiresolution analysis. IEEE Trans. Power Syst. 2001, 16, 4-662. [CrossRef]

26. Luo, G.M.; Yao, C.Y.; Liu, Y.L.; Tan, Y.J.; He, J.H. Entropy SVM-based recognition of transient surges in HVDC transmissions. Entropy Artic. 2018, 20, 421. [CrossRef] [PubMed] 
27. Chen, B.; Wang, J.; Zhao, H.; Principe, J.C. Insights into entropy as a measure of multivariate variability. Entropy 2016, 18, 196. [CrossRef]

28. Chen, B.; Zhu, Y.; Hu, J. Mean-square convergence analysis of ADALINE training with minimum error entropy criterion. IEEE Trans. Neural Netw. 2010, 21, 1168-1179. [CrossRef] [PubMed]

29. Ruiye, L.; Xin, S.; Zhimin, L. On the application of entropy in excitation control. In Proceedings of the 2004 International Conference on Power System Technology, PowerCon, Singapore, 21-24 November 2004; Volume 1, pp. 952-956.

30. Chen, J.; Li, G. Tsallis wavelet entropy and its application in power signal analysis. Entropy 2014, 16, 3009-3025. [CrossRef]

31. Luo, G.; Zhang, D.; Koh, Y.; Ng, K.; Leong, W. Time-Frequency entropy-based partial-discharge extraction for nonintrusive measurement. IEEE Trans. Power Deliv. 2012, 27, 1919-1927. [CrossRef]

32. Aggarwal, R.K.; Johns, A.T.; Bo, Z.Q. Non-unit protection technique for EHV transmission systems based on fault-generated noise, Part 2: Signal processing. IEE Proc. Gener. Transm. Distrib. 1994, 141, 141-147. [CrossRef]

33. Johns, A.T.; Martin, M.A.; Barker, A.; Walker, E.P.; Crossley, P.A. A new approach to E.H.V. direction comparisn protection using digital signal processing techniqles. IEEE Trans. Power Deliv. 1986, 1, 24-34. [CrossRef]

34. Qiang, G.; Xi, Y.; Ye, L. Circulating current suppressing and AC faults ride-through capability analysis of Zhoushan MMC-MTDC system. In Proceedings of the 2018 2nd IEEE Conference on Energy Internet and Energy System Integration (EI2), Beijing, China, 20-22 October 2018; pp. 1-6.

35. Abdalrahman, A.; Isabegovic, E. DolWin1-Challenges of connecting offshore wind farms. In Proceedings of the 2016 IEEE International Energy Conference (ENERGYCON), Piscataway, NJ, USA, 4-8 April 2016; pp. 1-10.

36. Ding, H.; Wu, Y.; Zhang, Y.; Ma, Y.; Kuffel, R. System stability analysis of Xiamen bipolar MMC-HVDC project. In Proceedings of the 12th IET International Conference on AC and DC Power Transmission (ACDC 2016), Beijing, China, 28-29 May 2016; pp. 1-6.

37. Hu, J.; Zhao, C.; Zhang, X.; Yang, X. Simulation study of the Zhoushan project as a three-terminal DC transmission system. In Proceedings of the 2012 IEEE Power and Energy Society General Meeting, San Diego, CA, USA, 22-26 July 2012 ; pp. 1-6.

38. You, M.; Zhang, B.H.; Cheng, L.Y.; Bo, Z.Q.; Klimek, A. Lightning model for HVDC transmission lines. In Proceedings of the 10th IET International Conference on Developments in Power System Protection (DPSP 2010). Managing the Change, Manchester, UK, 29 March-1 April 2010; pp. 1-5.

39. Luo, G.; Zhang, D.; Tseng, K.J.; He, J. Impulsive noise reduction for transient Earth voltage-based partial discharge using Wavelet-entropy. IET Sci. Meas. Technol. 2016, 10, 69-76.

40. Luo, G.M.; Lin, Q.Z.; Zhou, L.; He, J.H. Recognition of traveling surges in HVDC with wavelet entropy. Entropy 2017, 19, 184. [CrossRef]

41. Mallat, S.G. Wavelet basis. In A Wavelet Tour of Signal Processing: The Sparse Way; Elsevier: Amsterdam, The Netherlands; Academic Press: Boston, MA, USA, 2009; pp. 263-376. 